\title{
ПЕРСПЕКТИВЫ ИСПОЛЬЗОВАНИЯ РОССИЙСКОГО ВЫСОКРЕМНИСТОГО АЛЮМОСОДЕРЖАЩЕГО СЫРЬЯ В ГЛИНОЗЕМНОМ ПРОИЗВОДСТВЕ
}

\author{
Иванов Максим Анатольевич', \\ ivanov@misis.ru
}

Пак Вячеслав Игоревич',
pakvi@misis.ru

\author{
Наливайко Антон Юрьевич', \\ nalivaiko@misis.ru
}

\author{
Медведев Александр Сергеевич', \\ mas1941medvedev@yandex.ru
}

\author{
Киров Сергей Сергеевич', \\ kirovss@list.ru
}

\author{
Божко Галина Геннадьевна', \\ bojko06@mail.ru \\ ${ }^{1}$ Национальный исследовательский технологический университет «МИСиС»,
Россия, 119049, г. Москва, Ленинский пр., 4.
}

\begin{abstract}
Актуальность исследования обусловлена ограниченными запасами в нашей стране низкокремнистого алюмосодержащего сырья для производства металлургического глинозема по способу Байера. Поэтому руководство глиноземных комбинатов закупает данное сырье за рубежом (Гвинея, Бразилия, Ямайка). Стоимость транспортировки данного сырья с каждым годом становится все дороже и дороже, что повышает себестоимость металлургического глинозема. Также не стоит забывать о политических рисках, что еще больше усугубляет данную проблему. Следовательно, необходим переход на использование отечественного высококремнистого алюмосодержащего сырья, которое менее качественное, однако его запасы, находящиеся в непосредственной близости от глиноземных комбинатов, составляют сотни миллиардов.

Цель: исследование отечественной рудной базы высококремнистого алюминосодержащего сырья, определение первоочередных сырьевых источников и их месторождений, изучение характеристик сырья для оценки возможности его использования в производстве металлургического глинозема.

объект: высококремнистые алюмосодержащие каолиновые глины сибирских месторождений.

Проведенные исследования. Выполнен химический, фазовый, гранулометрический, микроструктурный, микрорентгеноспектральный и термогравиметрический анализы каолиновой глины Трошковского месторождения.

Результаты. Анализ отечественной рудной базы позволил выявить наиболее крупные месторождения высококремнистого алюминосодержащего сырья, пригодного для получения металлургического глинозема. Установлено, что наиболее перспективным является Трошковское месторождение. Преимуществами данного месторождения являются огромные запасы высококремнистого алюмосодержащего сырья, высокая степень изученности месторождения и благоприятные инженерно-геологические условия. Проведенные исследования каолиновой глины Трошковского месторождения позволили сделать вывод, что глина данного месторождения может быть использована для получения металлургического глинозема по кислотно-щелочной технологии.
\end{abstract}

\section{Ключевые слова:}

Высококремнистое алюмосодержащее сырье, каолиновая глина, импортозамещение, химический анализ, фазовый анализ, гранулометрический анализ, микроструктурный анализ, микрорентгеноспектральный анализ, термогравиметрический анализ.

\section{Введение}

На сегодняшний день Российская Федерация занимает лидирующую позицию в мире по объемам производства металлического алюминия, который получают путём электролиза криолито-глиноземного расплава. Из-за того, что в нашей стране имеется ограниченное количество низкокремнистых алюмосодержащих руд, возникает необходимость импортировать данное сырье для производства металлургического глинозема из-за рубежа, в частности из таких стран, как Гвинея, Бразилия, Ямайка.
Основная часть металлургического глинозема в нашей стране производится по способу Байера. Стоит отметить, что данный способ является самым распространенным способом получения металлургического глинозема в мире. Однако способ Байера применяется для выделения глинозема из бокситов с невысоким содержанием оксида кремния $\mathrm{SiO}_{2}$ (не более $5 \%$ ). При переработке бокситов с большим содержанием оксида кремния наблюдается высокий расход дорогостоящей щелочи, из-за чего способ становится экономически нецелесообразным. 
Логистика низкокремнистого алюмосодержащего сырья из-за рубежа с каждым годом становится менее рентабельной из-за роста стоимости его транспортировки. Анализируя вышесказанное, можно сделать вывод, что Российской глиноземной промышленности необходим переход на использование отечественного высококремнистого алюмосодержащего сырья.

В результате исследования отечественной рудной базы выявлены следующие сырьевые источники низкосортного высококремнистого алюминиевого сырья и их месторождения:

- глины (вскрышные и вмещающие породы угольных месторождений в Кемеровской области);

- каолины и аргиллиты, залегающие в непосредственной близости от Транссибирской железнодорожной магистрали;

- низкосортные бокситы и вмещающие аргиллитовые породы Чадобецкого месторождения в Нижнем Приангарье (Красноярский край);

- давсониты Кемеровской области;

- минералы силлиманитовой группы, пригодные для обогащения с получением концентратов, содержащих до $60 \% \mathrm{Al}_{2} \mathrm{O}_{3}$ (имеющиеся практически во всех южных регионах Сибири) [1].

Наиболее перспективным сырьем является высококремнистая каолиновая глина, запасы которой исчисляются сотнями миллионов тонн, находящимися в непосредственной близости от глиноземных предприятий нашей страны.

Барандатское месторождение каолиновой глины располагается в Тисульском районе Кемеровской области.

Каолиновая толща этого месторождения представлена глинами, составляющими 52,4 \% общего объёма толщи, алевролитами - 35,14 \%, песками - 7,54\%, нерабочими пропластками бурых углей - 2,34\% и сидеритами 2,58\%. Глинистое вещество состоит в основном из каолинита (80\%), примеси монтмориллонита, гидрослюды и каолинизированного полевого шпата и кварцевого песка. Залежь каолинов имеет пластообразную форму, расположенную на глубине около 65 м, при ее средней мощности 48 м.

Средневзвешенное содержание основных химических компонентов Барандатского месторождения с включением песчано-алевритовых и сидеритовых примесей составляет (масс. \%) $\mathrm{Al}_{2} \mathrm{O}_{3} 24,55$; $\mathrm{SiO}_{2} 54,45 ; \mathrm{Fe}_{2} \mathrm{O}_{3} 4,87 ; \mathrm{TiO}_{2} 1,39$ [2-4].

В результате лабораторных испытаний доказана возможность обогащения барандатских каолинов центрифугированием с повышением содержания $\mathrm{Al}_{2} \mathrm{O}_{3}$ в концентрате до 35-40 \% при выходе концентрата 60-75\% и извлечении $\mathrm{Al}_{2} \mathrm{O}_{3}$ до $85 \%$.

Жмуровское месторождение каолиновой глины расположено в Черемховском районе Иркутской области. Месторождение объединяет семь в разной степени опоискованных и разведанных участков общей площадью $144 \mathrm{~km}^{2}$, расположенных вблизи Транссибирской железной дороги. Химический состав каолиновой глины в зависимости от сортности представлен в табл. 1.

Месторождения глин Чадобецкого поднятия расположены в Красноярском крае вблизи Богучанского алюминиевого завода. Среднее содержание $\mathrm{Al}_{2} \mathrm{O}_{3}$ в данной группе месторождений варьируется от 17,6 до $28,8 \%$. Химический состав проб глин Чадобецкого поднятия представлен в табл. 2.

В качестве перспективного сырья для использования в глиноземном производстве выбрана као-

Таблица 1. Средний химический состав каолиновых глин Жмуровского месторождения

Table 1. Average chemical composition of kaolin clays of the Zhmurovsky deposit

\begin{tabular}{|c|c|c|c|c|c|c|c|c|c|c|c|c|}
\hline \multirow[b]{2}{*}{ Сорт/Grade } & \multicolumn{10}{|c|}{ Содержание, мac. \%/Content, wt. \% } & \multirow[b]{2}{*}{$\begin{array}{l}\text { Огнеупорность } \\
\text { Fire resistance, }{ }^{\circ} \mathrm{C}\end{array}$} & \multirow[b]{2}{*}{$\begin{array}{c}\text { Щебёнка } \\
\text { Breakstone, \% }\end{array}$} \\
\hline & $\mathrm{SiO}_{4}$ & $\mathrm{Al}_{2} \mathrm{O}_{3}$ & $\mathrm{TiO}_{2}$ & $\mathrm{Fe}_{2} \mathrm{O}_{3}$ & $\mathrm{CaO}$ & $\mathrm{MgO}$ & $\mathrm{R}_{2} \mathrm{O}$ & $\mathrm{SO}_{3}$ & $\begin{array}{l}\text { П.П.П. } \\
\text { L.O.I. }\end{array}$ & $\mathrm{H}_{2} \mathrm{O}$ & & \\
\hline I & 48,99 & 36,85 & 0,55 & 0,62 & 0,32 & 0,37 & 0,40 & 0,08 & 12,62 & 1,85 & 1730 & - \\
\hline II & 50,43 & 33,02 & 0,58 & 1,42 & 0,58 & 0,70 & 0,53 & 0,39 & 12,22 & 3,25 & 1710 & 3,79 \\
\hline III & 55,85 & 29,04 & 0,62 & 1,38 & 0,62 & 1,17 & 0,65 & 0,28 & 10,57 & 4,39 & 1790 & 27,48 \\
\hline $\begin{array}{l}\mathrm{HK} \\
\mathrm{NC}\end{array}$ & 72,93 & 11,69 & 0,57 & 4,84 & 0,50 & 2,22 & 2,14 & 0,94 & 4,84 & 3,16 & 1580 & 38,58 \\
\hline
\end{tabular}

Примечание: НК - запасы не кондиционных глин; П.П.П. - потери при прокаливании.

Note: NC-stocks of non-conditional clays; L.O.I. - loss of ignition.

Таблица 2. Хилический состав проб глин Чадобецкого поднятия

Table 2. Chemical composition of clay samples of the Chadobecky uplift

\begin{tabular}{|c|c|c|c|c|c|c|c|c|c|c|c|c|}
\hline \multirow{2}{*}{$\begin{array}{l}\text { № пробы } \\
\text { Sample no. }\end{array}$} & \multicolumn{12}{|c|}{ Содержание, масс. \%/Content, wt. \% } \\
\hline & $\mathrm{SiO}_{2}$ & $\mathrm{Al}_{2} \mathrm{O}_{3}$ & $\mathrm{Fe}_{2} \mathrm{O}_{3}$ & $\mathrm{TiO}_{2}$ & $\mathrm{P}_{2} \mathrm{O}_{5}$ & $\mathrm{CaO}$ & $\mathrm{MgO}$ & $\mathrm{Na}_{2} \mathrm{O}$ & $\mathrm{K}_{2} \mathrm{O}$ & $\mathrm{Cr}_{2} \mathrm{O}_{3}$ & $\mathrm{MnO}$ & $\begin{array}{c}\text { П.П.П. } \\
\text { L.0.I. }\end{array}$ \\
\hline 1 & 36,4 & 19,5 & 25,5 & 3,70 & 1,10 & 0,23 & 0,08 & 0,35 & $<0,15$ & 0,06 & 0,05 & 12,88 \\
\hline 2 & 41,8 & 28,8 & 10,8 & 3,50 & 0,67 & 0,16 & $<0,025$ & 0,28 & 0,39 & 0,02 & $<0,01$ & 13,55 \\
\hline 3 & 48,1 & 21,6 & 15,1 & 3,40 & 0,91 & 0,23 & $<0,025$ & 0,27 & $<0,15$ & 0,04 & $<0,01$ & 10,17 \\
\hline 4 & 55,8 & 17,6 & 4,30 & 0,62 & 0,12 & 2,70 & 2,80 & 2,50 & 1,30 & $<0.02$ & $<0,01$ & 12,46 \\
\hline
\end{tabular}

Примечание: П.П.П. - потери при прокаливании.

Note: L.O.I. - loss of ignition. 
таблица 3. Хилические составы каолиновых глин Трошковского месторождения

Table 3. Chemical compositions of kaolin clays of the Troshkovsky deposit

\begin{tabular}{|c|c|c|c|c|c|c|c|c|c|}
\hline $\begin{array}{l}\text { Copт } \\
\text { Grade }\end{array}$ & $\mathrm{SiO}_{2}$ & $\mathrm{Al}_{2} \mathrm{O}_{3}$ & $\mathrm{Fe}_{2} \mathrm{O}_{3}$ & $\mathrm{CaO}$ & $\mathrm{MgO}$ & $\mathrm{K}+\mathrm{Na}$ & $\mathrm{SO}_{3}$ & $\begin{array}{l}\text { П.П.П. } \\
\text { L.O.I }\end{array}$ & $\mathrm{H}_{2} \mathrm{O}$ \\
\hline I & $48-55$ & $33-38$ & $0,7-0,9$ & $0,3-0,9$ & $0,3-0,7$ & до 0,1 & до 0,4 & $9-13$ & $2-4$ \\
\hline II & $48-52$ & $34-37$ & $1-2$ & $0,2-0,8$ & $0,5-0,9$ & до 0,1 & до 0,2 & $9-13$ & $2-5$ \\
\hline III & $54-57$ & $26-32$ & $1-3$ & $0,2-1,2$ & до 2 & до 0,4 & до 0,3 & $8-12$ & $2-8$ \\
\hline
\end{tabular}

Примечание: П.П.П. - потери при прокаливании.

Note: L.O.I. - loss of ignition.

линовая глина Трошковского месторождения. Выбор в пользу каолиновой глины Трошковского месторождения был сделан из-за огромных разведанных запасов и низкого содержания в глинах активных примесных оксидов $\mathrm{Fe}_{2} \mathrm{O}_{3}, \mathrm{TiO}_{2}, \mathrm{CaO}, \mathrm{MgO}$, $\mathrm{Na}_{2} \mathrm{O}, \mathrm{K}_{2} \mathrm{O}$, суммарное содержание которых не превышает 4,5 \%. Трошковское месторождение каолиновой глины находится в 3 километрах от станции Половина Транссибирской железнодорожной магистрали (Иркутская область). Химический состав каолиновой глины Трошковского месторождения различной сортности представлен в табл. 3 .

Высококремнистое алюмосодержащее сырье может быть эффективно переработано солянокислотным способом [5]. Именно в солянокислотной реализации технологической схемы переработки высококремнистого алюминосодержащего сырья легче всего осуществляется регенерация соляной кислоты по сравнению с серной и азотной кислотами [6]. Регенерация кислоты сводится к улавливанию паров соляной кислоты водой после термогидролиза кристаллов хлористого алюминия и железа [7]. Полученную соляную кислоту в дальнейшем можно использовать для головной операции выщелачивания новой порции исходного алюминийсодержащего сырья.

Соляная кислота имеет ряд неоспоримых преимуществ перед другими минеральными кислотами: - относительно простой способ вскрытия руды с последующим переводом ценного компонента (оксида алюминия) в раствор;

- низкий уровень растворимости кремния в соляной кислоте;

- возможность практически полного удаления оксида кремния (сиштофа) без потерь соляной кислоты;

- возможность регенерации соляной кислоты и её повторное использование на переделе выщелачивания новой порции алюмосодержащего сырья [8-10].

До настоящего времени не было возможности перерабатывать огромные запасы высококремнистого алюмосодержащего сырья из-за отсутствия технологии переработки, которая бы позволяла получать глинозем, соответствующий металлургическому качеству.

Для переработки отечественных каолиновых глин была разработана комплексная кислотно-щелочная технология, позволяющая уже на первой стадии технологического цикла отделить соединения алюминия от пустой породы (оксид кремния) и в конечном итоге получить глинозем металлургического качества [11-14]. Комплексная кислотно-щелочная технология переработки высококремнистого алюмосодержащего сырья заключается в автоклавном выщелачивании каолиновой глины [15-17] с получением алюмохлоридного раствора. Далее алюмохлоридный раствор подвергается операции фильтрации с целью отделения пустой породы (сиштоф) $[18,19]$. Через осветленный алюмохлоридный раствор продувают газообразный хлороводород, в результате чего из раствора выпадает гексагидрат хлорида алюминия (ГХА) [20]. Полученные кристаллы подвергают операции кальцинации с получением чернового глинозема [21]. Черновой глинозем подвергают двухстадийному выщелачиванию щелочью в атмосферных и автоклавных условиях с получением алюминатного раствора. Полученный алюминатный раствор подвергают операции декомпозиции с образованием гидроксида алюминия. Далее полученный гидроксид алюминия прокаливают с получением металлургического глинозема согласно ГОСТ 30558-98 «Глинозем металлургический».

Возможность привлечения российского низкокачественного высококремнистого алюмосодержащего сырья для производства глинозема позволит заменить импортное сырье на отечественное, что при огромной текущей потребности алюминиевых заводов России в глиноземе позволит получить колоссальный экономический эффект от импортозамещения [22].

\section{Анализ каолиновой глины}

\section{Трошковского месторождения}

Химический состав каолиновой глины был изучен при помощи рентгенофлуоресцентного спектрометра ARL OPTIM'X. Результаты химического анализа каолиновой глины представлены в табл. 4 .

Изучаемая каолиновая глина характеризуется высоким содержанием оксида алюминия $\left(\mathrm{Al}_{2} \mathrm{O}_{3} \approx 31 \%\right)$, что делает данное сырье перспективным для переработки с целью получения глинозема. При повышенном содержания оксида кремния $\left(\mathrm{SiO}_{3} \approx 31 \%\right)$ каолиновая глина относится к низкосортному алюмосодержащему сырью с низ ким кремневым модулем $\mu_{\mathrm{Si}}=\frac{\mathrm{Al}_{2} \mathrm{O}_{3}}{\mathrm{SiO}_{2}}=0,62$. 
Таблица 4. Хилический состав каолиновой глины Table 4. Chemical composition of kaolin clay

\begin{tabular}{|c|c|}
\hline Компонент/Component & Содержание, мaс. \%/Content, wt. \% \\
\hline $\mathrm{SiO}_{2}$ & 50,76 \\
\hline $\mathrm{Al}_{2} \mathrm{O}_{3}$ & 31,49 \\
\hline $\mathrm{Fe}_{2} \mathrm{O}_{3}$ & 1,31 \\
\hline $\mathrm{TiO}_{2}$ & 0,52 \\
\hline $\mathrm{P}_{2} \mathrm{O}_{5}$ & 0,07 \\
\hline $\mathrm{CaO}$ & 0,46 \\
\hline $\mathrm{MgO}$ & 0,99 \\
\hline $\mathrm{Na}_{2} \mathrm{O}$ & 0,04 \\
\hline $\mathrm{K}_{2} \mathrm{O}$ & 0,19 \\
\hline $\mathrm{V}_{2} \mathrm{O}_{5}$ & 0,01 \\
\hline $\mathrm{SO}_{3}$ & 0,02 \\
\hline П.П.П. & 14,14 \\
\hline L.O.I. & \\
\hline
\end{tabular}

Прилечание: П.П.П. - потери при прокаливании.

Note: L.O.I. - loss of ignition.
Фазовый анализ каолиновой глины был изучен при помощи рентгенофлуоресцентного спектрометра со встроенным дефрактором ARL 9900 Workstation. Было установлено, что основными минералами, входящими в состав каолиновой глины, являются:

- каолинит $\mathrm{Al}_{2} \mathrm{Si}_{2} \mathrm{O}_{5}(\mathrm{OH})_{4} \approx 64,58$, мас. \%;

- монтмориллонит $\mathrm{Al}_{2} \mathrm{Si}_{4} \mathrm{O}_{10}(\mathrm{OH})_{2} \cdot \mathrm{nH}_{2} \mathrm{O} \approx 24,31$, мас. \%; - кварц $\mathrm{SiO}_{2} \approx 6,61$, мас. \% .

Дифрактограмма каолиновой глины представлена на рис. 1. В составе каолиновой глины присутствуют два алюмосодержащих минерала (каолинит и монтмориллонит). Ввиду того, что каолинит малорастворим в соляной кислоте, необходим его перевод в более легковскрываемую форму - метакаолинит $\left(\mathrm{Al}_{2} \mathrm{O}_{3} \cdot 2 \mathrm{SiO}_{2}\right.$ или $\left.\mathrm{Al}_{2} \mathrm{Si}_{2} \mathrm{O}_{7}\right)$. Для этого необходим предварительный обжиг каолиновой глины.

Гранулометрический анализ каолиновой глины был изучен при помощи лазерного анализатора размеров частиц МикроСайзер 201C (Рос-

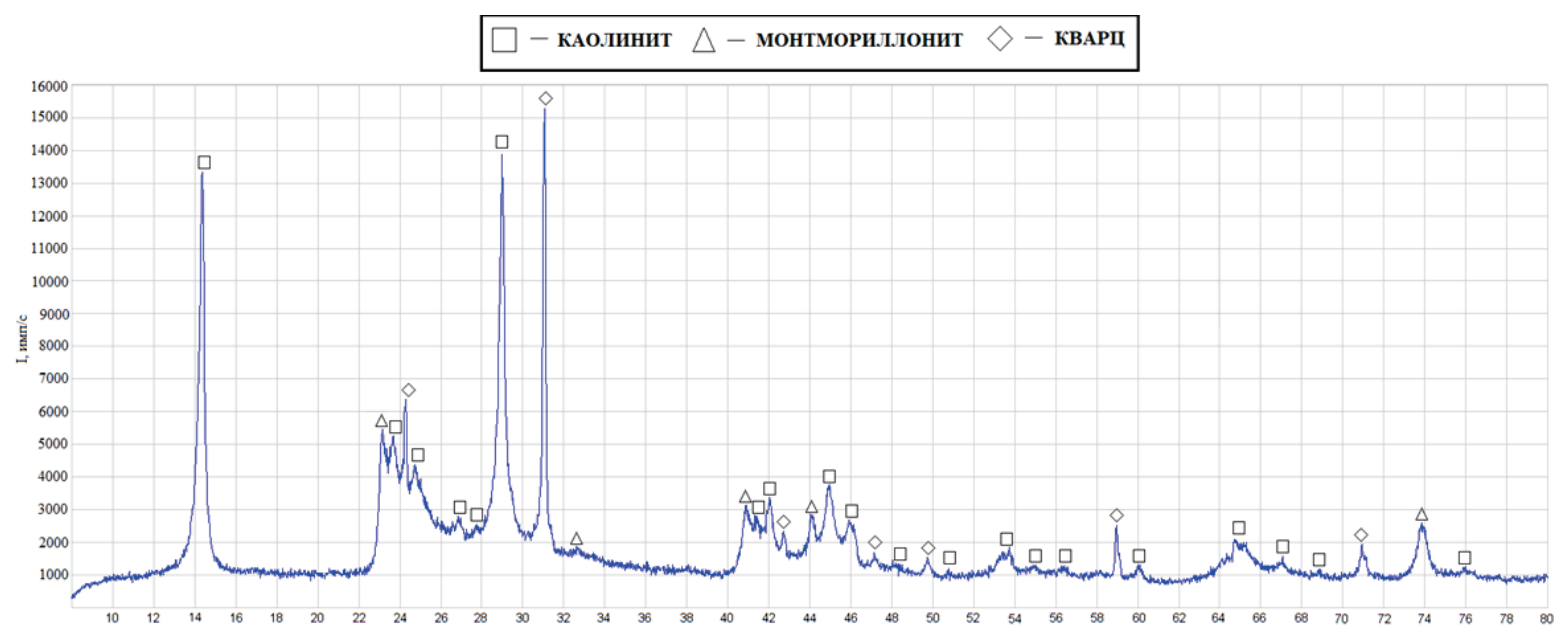

Pис. 1. Дифрактограмма каолиновой глины

Fig. 1. Diffractogram of kaolin clay

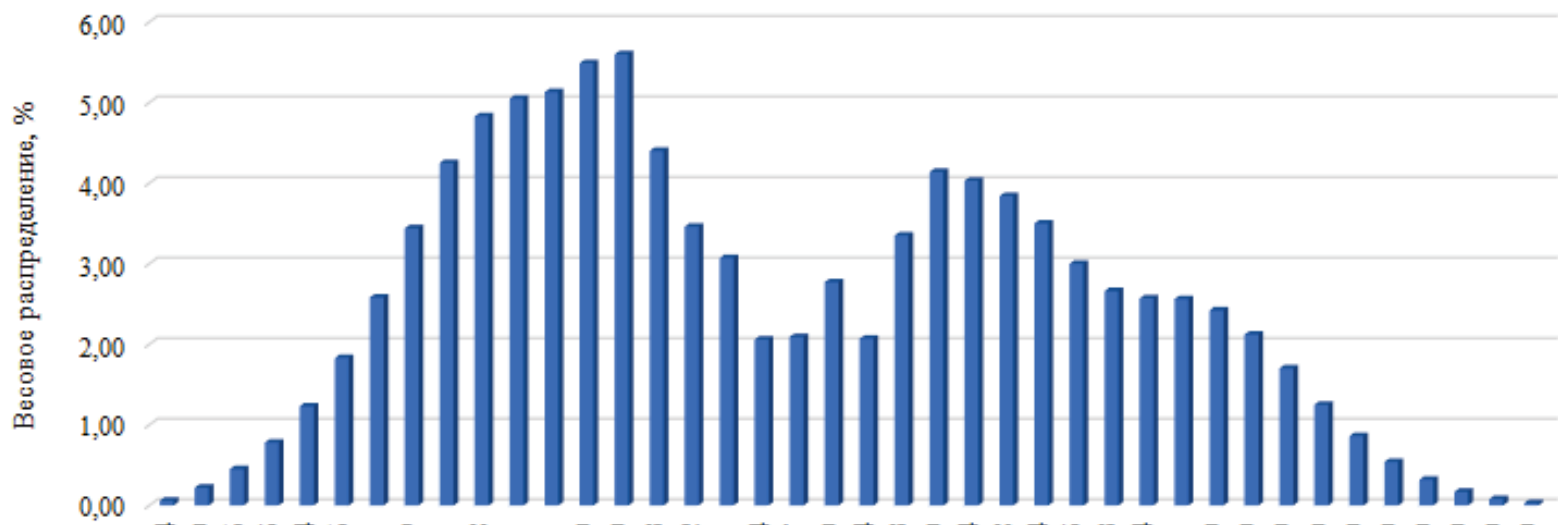

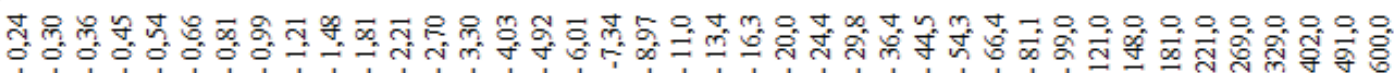

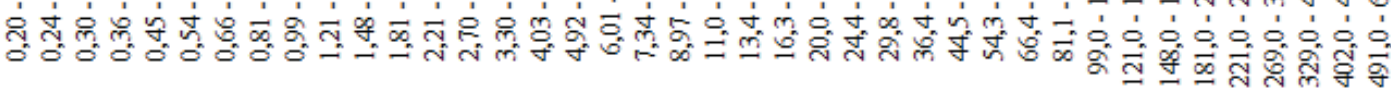

\section{Диаметр частиц, мкм}

Pис. 2. Гистограмла распределения размеров частии исходной каолиновой глины

Fig. 2. Histogram of particle size distribution of initial kaolin clay 
сия). Гистограмма распределения размеров частиц исходной каолиновой глины представлена на рис. 2.

Было установлено, что каолиновая глина состоит из агломератов размером от 0,20 до 600 мкм, при этом массовое содержание фракции менее 100 мкм составляет $93 \%$. Такая тонкость помола каолиновой глины является приемлемой ввиду отсутствия пылевыноса при загрузке в реактор и быстрого растворения в соляной кислоте.
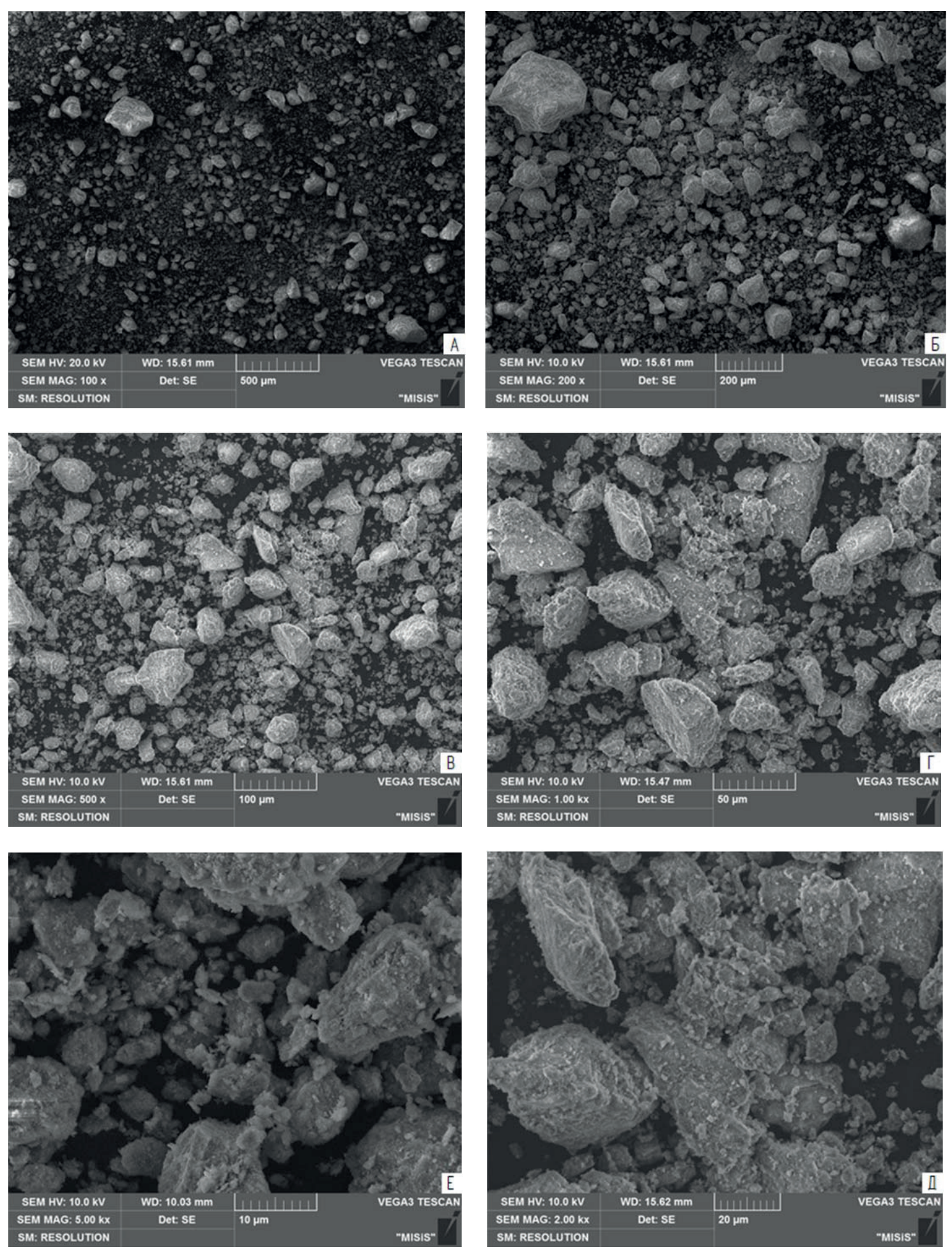

Рис. 3. Микрофотографии пространственного расположения частии каолиновой глины при различном увеличении: $A-\mathrm{x} 100,5-\mathrm{x} 200$, $B-\mathrm{x} 500, \Gamma-\mathrm{x} 1000, Д-\mathrm{x} 2000, E-\mathrm{x} 5000$

Fig. 3. Microphotographs of spatial arrangement of kaolin clay particles at different magnification: $A-\mathrm{x} 100, B-\mathrm{x} 200, B-\mathrm{x} 500, \Gamma-\mathrm{x} 1000$, Д- x 2000, E-x5000 
Были сделаны микрофотографии частиц каолиновой глины, а также проведен рентгеновский микроанализ спектров. Анализ проводился с использованием электронной микроскопии («Tescan Vega 3SB» (Чехия)) с приставкой микрорентгеноспектрального анализа (энерго-дисперсионный спектрометр «0xford X-Act 10mm (Англия)).

Микрофотографии частиц каолиновой глины при различном увеличении представлены на рис. 3.

Микрофотография частиц каолиновой глины с отмеченными точками микрорентгенспектрального анализа представлена на рис. 4.

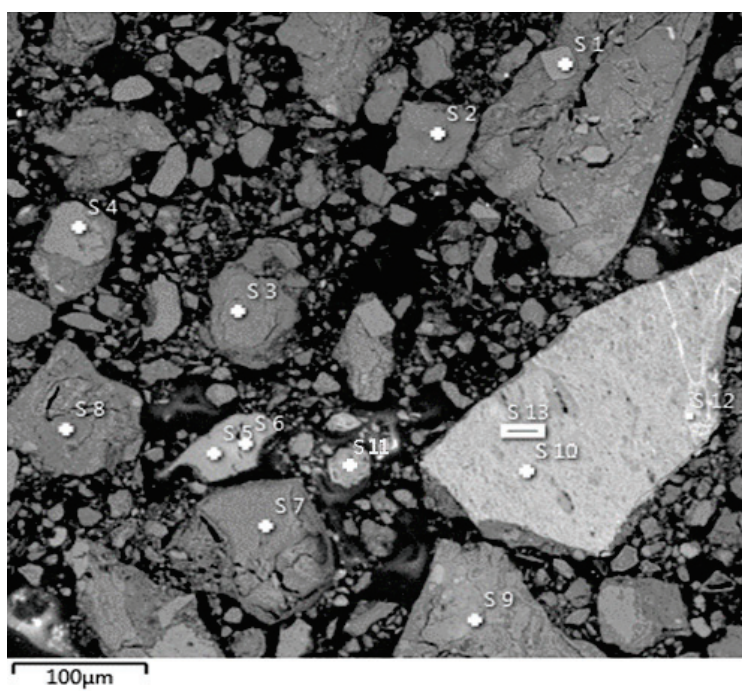

Рис.4. Микрофотография каолиновой глины с отмеченныли точками микрорентгенспектрального анализа

Fig. 4. Microphotograph of kaolin clay with marked micro-X-ray spectral analysis
Результаты микрорентгенспектрального анализа каолиновой глины представлены в табл. 5 .

Таблица 5. Результаты микрорентгенспектрального анализа Table 5. Results of micro-X-ray spectral analysis

\begin{tabular}{|c|c|c|c|c|c|c|c|c|}
\hline № спектра & \multicolumn{8}{|c|}{ Содержание, мас. \%/Content, wt. \% } \\
\cline { 2 - 9 } Spectrum no. & 0 & $\mathrm{Al}$ & $\mathrm{Si}$ & $\mathrm{Fe}$ & $\mathrm{Ti}$ & $\mathrm{Ca}$ & $\mathrm{K}$ & $\mathrm{Mg}$ \\
\hline S 1 & 57,7 & 9,8 & 30,1 & 1,3 & 0,3 & - & 0,8 & - \\
\hline S 2 & 66,2 & 26,7 & 5,6 & 0,4 & - & 0,4 & 0,3 & 0,4 \\
\hline S 3 & 61,6 & 27,6 & 4,9 & 2,8 & 0,8 & 1,6 & 0,7 & - \\
\hline S 4 & 45,6 & 8,6 & 21,8 & - & 20,1 & 1,8 & 0,9 & 1,2 \\
\hline S 5 & 48,9 & 9,1 & 4,2 & 2,2 & 34,5 & 1,1 & - & - \\
\hline S 6 & 50,4 & 8,2 & 4,3 & 1,8 & 33,3 & 2,0 & - & - \\
\hline S 7 & 65,4 & 26,5 & 3,2 & 2,2 & 0,5 & 1,2 & 0,4 & 0,6 \\
\hline S 8 & 57,3 & 36,2 & 3,8 & - & 1,2 & 0,7 & - & 0,8 \\
\hline S 9 & 47,9 & 4,3 & 22,9 & 7,4 & 17,1 & 0,4 & - & - \\
\hline S 10 & 58,7 & 8,4 & 4,4 & 26,8 & 1,1 & - & 0,6 & - \\
\hline S 11 & 40,8 & 5,1 & 2,7 & 24,1 & 26,4 & 0,3 & 0,2 & 0,4 \\
\hline S 12 & 59,4 & 7,6 & 4,1 & 27,6 & 0,8 & - & 0,5 & - \\
\hline S 13 & 50,7 & 9,7 & 3,8 & 34,1 & 0,6 & - & 1,1 & - \\
\hline
\end{tabular}

На микрофотографии каолиновой глины алюминий преимущественно представлен частицами темного цвета (рис. 4, спектры S 2, S 3, , 7 , S 8), светлые участки соответствуют более тяжелым элементам, таким как кремний (рис. 4, спектры S $1, \mathrm{~S} 4, \mathrm{~S} 9$ ), железо (рис. 4, спектры S $10, \mathrm{~S} 11, \mathrm{~S} 12, \mathrm{~S} 13$ ) и титан (рис. 4, спектры S 4, S 5, S 6, S 9, S 11).

Для регистрации изменения массы образца исходной каолиновой глины в условиях программированного изменения температуры среды был проведен термогравиметрический анализ на термоанализаторе SDTQ600, позволяющий одновременно проводить дифференциальный сканирующий калориметрический (ДСК) и термогравиметрический (ТГ) анализы (рис. 5). Прежде всего, это

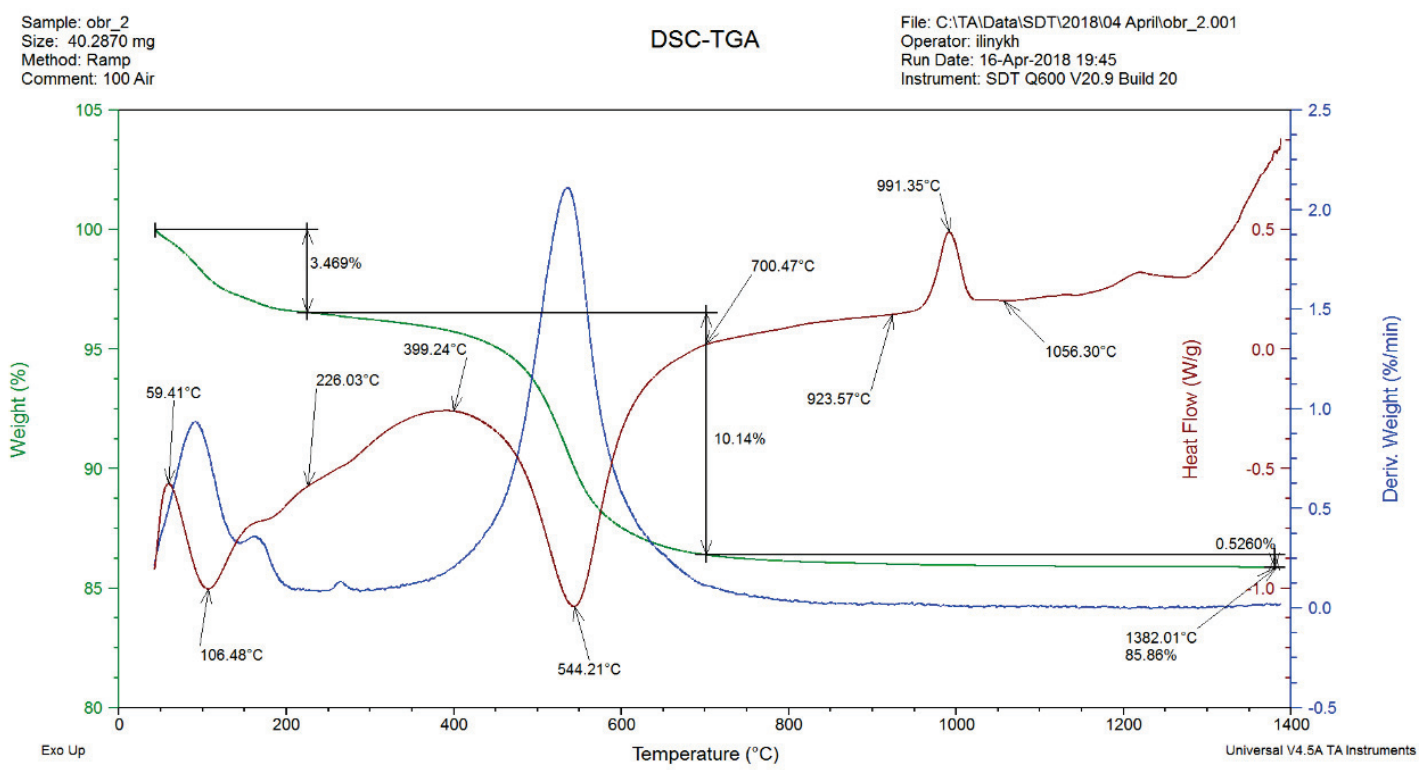

Рис.5. Термогравиметрические кривые дифференииального сканирующего калориметрического (ДСК) и терлогравиметрического (ТГ) анализов

Fig. 5. Thermogravimetric curves of differential scanning calorimetric (DSC) and thermogravimetric (TG) analyses 
необходимо для того, чтобы определить температуру дегидратации и связанных с ней фазовых переходов. Эксперимент заключался в линейном нагреве каолиновой глины до $1400{ }^{\circ} \mathrm{C}$ со скоростью нагрева $25{ }^{\circ} \mathrm{C} /$ мин в атмосфере воздуха. В низкотемпературной области на термограмме наблюдается незначительный эндотермический пик в интервале температур от 60 до $226{ }^{\circ} \mathrm{C}$, связанный с удалением адсорбированной воды из каолиновой глины. На термограмме отчетливо виден второй эндотермический пик в интервале температур $400-700{ }^{\circ} \mathrm{C}$. В этом температурном диапазоне происходит существенная потеря массы каолиновой глины, соответствующая удалению воды, химически связаной с минералами, входящими в состав каолиновой глины [23].

На первом этапе масса каолиновой глины уменьшается примерно на 3,5 \% , на втором этапе потеря массы составляет примерно $10 \%$. Существенная потеря массы каолиновой глины на втором этапе связана с тем, что дегидратации подвергаются такие минералы, как каолинит и монтмориллонит, массовая доля которых является самой значительной в каолиновой глине. На третьем этапе при нагреве до $1400{ }^{\circ} \mathrm{C}$ уменьшение массы каолиновой глины минимально и составляет менее $1 \%$. Суммарное изменение массы исходной каолиновой глины при нагреве до $1400{ }^{\circ} \mathrm{C}$ составляет $14,14 \%$.

Стоит отметить, что обжиг высококремнистого алюмосодержащего сырья при температуре выше $800{ }^{\circ} \mathrm{C}$ недопустим [24, 25], так как при указанной

\section{СПИСОК ЛИТЕРАТУРЫ}

1. The Influence of the Mineral Composition of Low-Grade Aluminium Ores on Aluminium Extraction by Acid Leaching / A. Suss, A. Damaskin, A. Senyuta, A. Panov, A. Smirnov // Light Metals. - 2014. - V. 1. - P. 105-109.

2. Отто М. Современные методы аналитической химии. - М.: Техносфера, 2008. - $544 \mathrm{c}$.

3. Tan J. Kim S. C. Understanding advanced physical inorganic chemistry. The Learner's Approach. - World Scientific. - 2011. V. $12 .-472 \mathrm{p}$.

4. Vetchinkina T.N. Physicochemical properties of the alumina produced by alkaline and acidic methods // Russian Metallurgy (Metally). - 2009. - V. 2. - P. 120-128.

5. Лысенко А.П., Шиловский С.Ю., Кондратьева Е.С. Совмещенные способы получения алюминиевых сплавов // Цветные металлы. - 2018. - № 9. - С. 35-39.

6. Лайнер Ю.А. Комплексная переработка алюминий-содержащего сырья кислотными способами. - М.: Наука, 1982. 208 c.

7. Состояние и перспективы развития кислотных способов получения глинозема / А.В. Панов, А.С. Сенюта, А.Г. Сусс, Ю.А. Лайнер // «Цветные металлы-2012»: Сборник научных статей. - Красноярск: Версо, 2012. - С. 272-277.

8. Мирзоев Д.Х., Каюмов А.М., Худойкулов М.М. Азотнокислотное разложение аргиллитов месторождения Зидды Республики Таджикистан // Доклады Академии Наук Республики Таджикистан. - 2012. - Т. 55. - № 2. - С. 141-144.

9. Запольский А.К. Сернокислотная переработка высококремнистого алюминиевого сырья. - Киев.: Наукова думка, 1981. 208 c. температуре образуется нерастворимый в соляной кислоте муллит $\left(3 \mathrm{Al}_{2} \mathrm{O}_{3} \cdot 2 \mathrm{SiO}_{2}\right)$.

\section{Заключение}

В результате исследования отечественной рудной базы выявлены наиболее крупные месторождения низкосортного высококремнистого алюмосодержащего сырья, пригодного для получения глинозема кислотно-щелочным способом. Выявлено, что наиболее перспективным является Трошковское месторождение каолиновой глины. Преимуществами Трошковского месторождения являются огромные запасы каолиновой глины, высокая степень изученности месторождения и благоприятные инженерногеологические условия и приближенность к транссибирской железнодорожной магистрали.

В результате проведенных исследований было установлено, что каолиновая глина Трошковского месторождения полностью соответствует требованиям, предъявляемым к исходному сырью для кислотно-щелочной технологии получения металлургического глинозема, по содержанию целевого компонента $\left(\mathrm{Al}_{2} \mathrm{O}_{3} \approx 31 \%\right.$ ), фазовому составу (алюмосодержащие минералы - каолинит и монтмориллонит) и тонкости помола (массовое содержание фракции менее 100 мкм - $93 \%$ ).

Авторы выражают благодарность заведующему кафедрой иветных металлов и золота НИТУ «МИСИС» В.П.Тарасову за поддержку в процессе работы над статьей, а также значимые замечания и важнейшие советы при проведении исследований.

10. Лайнер А.И. Производство глинозема. - М.: Государственное научно-техническое издательство литературы по черной и цветной металлургии, 1961. -620 c.

11. Innovative Technology for alumina production from low-grade raw materials / A. Senyuta, A. Panov, A. Suss, Y. Layner // Minerals, Metals and Materials Series. - 2016. - Iss. 210869. P. 203-208.

12. Особенности поведения различных $\mathrm{Al}-\mathrm{Si}$ минералов при соляно-кислотном вскрытии небокситового сырья Сибири / А.Г. Сусс, А.А. Дамаскин, А.С. Сенюта и др. // 31 Международная конференция ICSOBA: Сборник научных статей. Красноярск: Версо, 2013. - С. 433-438.

13. Miniplant tests of $\mathrm{HCl}$ technology of alumina production / A. Smirnov, D. Kibartas, A. Senyuta, A. Panov // Minerals, Metals and Materials Series. - 2018. - V. 1. - P. 57-62.

14. Испытание экспериментального комплекса получения глинозема по кислотному способу из высококремнистого алюминиевого сырья / Б.Г. Балмаев, В.И. Пак, М.А. Иванов, А.А. Смирнов // Цветные металлы и минералы: IX Международный конгресс. Сборник тезисов докладов. - Красноярск, 2013. - С. 184-185.

15. Liu K., Xue J., Zhu J. Extracting alumina from coal fly ash using acid sintering-leaching process // Light Metals. - 2012. P. 201-206.

16. Кинетика высокотемпературного солянокислотного выщелачивания каолиновых глин восточносибирских месторождений в лабораторных и укрупненных условиях / Б.Г. Балмаев, С.С. Киров, В.И. Пак, М.А. Иванов // Цветные металлы. 2018. - № 3. - C. 38-45.

17. Wu Cheng-you, Yu Hong-fa, Zhang Hui-fang. Extraction of aluminum by pressure acid-leaching method from coal fly ash // 
Transactions of Nonferrous Metals Society of China. - 2012. V 9. - P. 2282-2288.

18. Study of filtration and washing of residue after HCL leaching of kaolin clay / A.S. Senyuta, A.V. Panov, A.A. Damaskin, A.A. Smirnov // Light Metals. - 2015. - V 2. - P. 127-130.

19. Моделирование процесса фильтрования алюминийсодержащей солянокислой пульпы / Б.Г. Балмаев, С.С. Киров, М.А. Иванов, В.И. Пак // Цветные металлы. - 2017. - № 10. C. 63-68.

20. Identification of the hydrolysis products of $\mathrm{AlCl}_{3} \cdot 6 \mathrm{H}_{2} \mathrm{O}$ by electrospray ionization mass spectrometry / A. Sarpola, V. Hietapelto, J. Jalonen, J. Jokela, R.S. Laitinen // Journal of Mass Spectrometry. - 2004. - V. 39. - P. 423-430.

21. Thermolysis of acidic aluminum chloride solution and its products / V.V. Ivanov, S.D. Kirik, A.A. Shubin, I.A. Blokhina, V.M. Denisov, L.A. Irtugo // Ceramics International. - 2013. V. 39. - Iss. 4. - P. 3843-3848.
22. Feasibility Assessment for Leucosapphire Production from Aluminum Oxide Prepared Electrochemically / A.Yu. Nalivaiko, A.P. Lysenko, V.I. Pak, M.A. Ivanov // Refractories and Industrial Ceramics. - 2018. - V. 55. - № 1. - P. 80-84.

23. Yilmaz G. The effects of temperature on the characteristics of kaolinite and bentonite // Scientific research and essays - 2011. V. 6. - P. 1928-1939.

24. Al-Zahrani A.A., Abdul-Majid M.H. Extraction of alumina from Local Clays by Hydrochloric Acid Process // Journal of King Abdulaziz University: Engineering Sciences. - 2009. - V. 20. Iss. 2. - P. 29-41.

25. Extraction of Alumina from high-silicon bauxite by hydrochloric acid leaching using preliminary roasting method / D.V. Valeev, E.R. Mansurova, V.A. Bychinskii, K.V. Chudenko // IOP Conference Series: Materials Science and Engineering, 2013. - V. 1. Iss. 1. - P. 012049.

Поступила 28.01.2019 2.

\section{Информация об авторах}

Иванов М.А., аспирант кафедры цветных металлов и золота Национального исследовательского технологического университета «МИСиС».

Пак В.И., аспирант кафедры цветных металлов и золота Национального исследовательского технологического университета «МИСиС».

Наливайко А.Ю., кандидат технических наук, старший преподаватель кафедры цветных металлов и золота Национального исследовательского технологического университета «МИСиС».

Медведев А.С., доктор технических наук, профессор кафедры цветных металлов и золота Национального исследовательского технологического университета «МИСиС».

Киров С.С., кандидат технических наук, доцент кафедры цветных металлов и золота Национального исследовательского технологического университета «МИСиС».

Божко Г.Г., кандидат технических наук, доцент кафедры цветных металлов и золота Национального исследовательского технологического университета «МИСиС». 
UDC 66.014

\title{
PROSPECTS OF USING RUSSIAN HIGH-SILICON RAW MATERIALS IN ALUMINA PRODUCTION
}

\author{
Maxim A. Ivanov', \\ ivanov@misis.ru
}

\section{Vyacheslav I. Pak', pakvi@misis.ru}

\section{Anton Yu. Nalivayko',} nalivaiko@misis.ru

\section{Alexander S. Medvedev', mas1941medvedev@yandex.ru}

\section{Sergey S. Kirov', \\ kirovss@list.ru}

\section{Galina G. Bozhko',} bojk006@mail.ru

\author{
'National University of Science and Technology «MISIS», \\ 4, Leninsky avenue, Moscow, 119049, Russia.
}

\begin{abstract}
The relevance of the research is caused by the limited reserves of low-silicon aluminum-containing raw materials for production of metallurgical alumina by the Bayer method in our country. Therefore, the management of alumina plants buys this raw materials abroad (Guinea, Brazil, Jamaica). The cost of transportation of this raw material every year becomes more and more expensive, which increases the cost of metallurgical alumina. Also, do not forget about political risks, which further aggravates this problem. Therefore, it is necessary to switch to the use of domestic high-silicon aluminum-containing raw materials of lower quality, but their reserves, located in close proximity to alumina plants, are hundreds of billions of tons.

The aim of the research is to study the domestic ore base of high-silicon aluminum-containing raw materials, to define primary sources of raw materials and their deposits, to investigate the characteristics of raw materials to assess the possibility of their use for production of metallurgical alumina.

Object: high-silicon aluminum-containing kaolin clay of Siberian deposits.

Conducted research. Chemical, phase, granulometric, microstructural, micro-x-ray spectral and thermogravimetric analyses of kaolin clay of Troshkovsky Deposit were performed.

Results. The analysis of the domestic ore base revealed the largest deposits of low-grade aluminum-containing raw materials suitable for production of metallurgical alumina. It is established that the most promising is the Troshkovsky Deposit. The advantages of this field are huge reserves of high-silicon aluminum-containing raw materials, a high degree of study of the field and favorable engineeringgeological conditions. The conducted research of the Troshkovsky kaolin clay deposits have led to conclusion that the clay of this field can be used for production of metallurgical alumina by acid-alkaline technology.
\end{abstract}

\section{Key words:}

High-silicon aluminum-containing raw materials, kaolin clay, import substitution, chemical analysis, phase analysis, granulometric analysis, microstructural analysis, micro-x-ray spectral analysis, thermogravimetric analysis.

The authors are grateful to the head of the department of non-ferrous metals and gold NUST «MISIS»V.P. Tarasov for support in the process of working on the article, as well as significant comments and important advice when conducting research.

\section{REFERENCES}

1. Suss A., Damaskin A., Senyuta A., Panov A., Smirnov A. The Influence of the Mineral Composition of Low-Grade Aluminium Ores on Aluminium Extraction by Acid Leaching. Light Metals, 2014, vol. 1, pp. 105-109.

2. Otto M. Souremennye metody analiticheskoy khimii [Modern methods of analytical chemistry]. Moscow, Tekhnosfera Publ., 2008. $544 \mathrm{p}$.

3. Tan J. Kim S. C. Understanding advanced physical inorganic che mistry. The Learner's Approach. World Scientific, 2011, vol. 12 , $472 \mathrm{p}$.

4. Vetchinkina T.N. Physicochemical properties of the alumina produced by alkaline and acidic methods. Russian Metallurgy (Metally), 2009, vol. 2, pp. 120-128.
5. Lysenko A.P., Shilovsky S.Yu., Kondrateva E.S. Combined methods for production of aluminum alloys. Tsvetnye metally, 2018, no. 9, pp. 35-39. In Rus.

6. Layner Yu.A. Kompleksnaya pererabotka alyuminiy-soderzhashchego syrya kislotnymi sposobami [Complex processing of aluminum-containing raw materials by acidic methods]. Moscow, Nauka Publ., 1982. 208 p.

7. Panov A.V., Senyuta A.S., Suss A.G., Layner Yu.A. Sostoyanie i perspektivy razvitiya kislotnykh sposobov polucheniya glinozema [Status and prospects of development of acidic methods of alumina production]. "Tsvetnye metally-2012». Sbornik nauchnykh statey [Non-ferrous metals-2012. Compilation of scientific articles]. Krasnoyarsk, Verso Publ., 2012. pp. $272-277$. 
8. Mirzoev D.H., Kayumov A.M., Hudoykulov M.M. Nitric acid decomposition of Zidda Deposit's argillits of the Republic of Tajikistan. The Republic Of Tajikistan's Academy of Sciences reports, 2012, vol. 55, no. 2, pp. 141-144. In Rus.

9. Zapolsky A.K. Sernokislotnaya pererabotka vysokokremnistogo alyuminievogo syrya [Sulfuric acid processing of high-silicon aluminum raw materials]. Kiev, Naukova dumka Publ., 1981. 208 p.

10. Layner A.I. Proizvodstvo glinozema [Alumina production]. Moscow, State scientific and technical publishing house of literature on ferrous and non-ferrous metallurgy, $1961.620 \mathrm{p}$.

11. Senyuta A., Panov A., Suss A., Layner Y. Innovative Technology for alumina production from low-grade raw materials. Minerals, Metals and Materials Series, 2016, Iss. 210869, pp. 203-208.

12. Suss A.G., Damaskin A.A., Senyuta A.S. Osobennosti povedeniya razlichnykh Al-Si mineralov pri solyano-kislotnom vskrytii neboksitovogo syrya Sibiri [Behaviors of various AlSi minerals with hydrochloric acid autopsy of reboxetine raw materials in Siberia]. 31 Mezhdunarodnaya konferentsiya ICSOBA: Sbornik nauchnykh statey [Proc. of the $31^{\text {th }}$ International conference ICSOBA]. Krasnoyarsk, Verso Publ., 2013. pp. 433-438.

13. Smirnov A., Kibartas D., Senyuta A., Panov A. Miniplant tests of $\mathrm{HCl}$ technology of alumina production. Minerals, Metals and $\mathrm{Ma}$ terials Series, 2018, vol. 1, P. F4, pp. 57-62.

14. Balmaev B.G., Pak V.I., Ivanov M.A., Smirnov A.A. Ispytanie eksperimentalnogo kompleksa polucheniya glinozema po kislotno$\mathrm{mu}$ sposobu iz vysokokremnistogo alyuminievogo syrya [Testing of the experimental complex for production of alumina by the acid method from high-silicon aluminum raw materials]. IX Mezhdunarodny kongress "Tsvetnye metally $i$ mineraly». Sbornik tezisov dokladov [IX International Congress «Non-ferrous metals and minerals»: Book of abstracts]. Krasnoyarsk, 2013. pp. 184-185.

15. Liu K., Xue J., Zhu J. Extracting alumina from coal fly ash using acid sintering-leaching process. Light Metals, 2012, pp. 201-206.

16. Balmaev B.G., Kirov S.S., Pak V.I., Ivanov M.A. Kinetics of high-temperature hydrochloric leaching of kaolin clays of eastSiberian deposits in laboratory conditions and pilot plant tests. Tsvetnye metally, 2018, no. 3, pp. 38-45. In Rus.
17. Wu Cheng-you, Yu Hong-fa, Zhang Hui-fang. Extraction of aluminum by pressure acid-leaching method from coal fly ash. Transactions of Nonferrous Metals Society of China, 2012, vol. 9, pp. 2282-2288.

18. Senyuta A.S., Panov A.V., Damaskin A.A., Smirnov A.A. Study of filtration and washing of residue after HCL leaching of kaolin clay. Light Metals, 2015, vol. 2, pp. 127-130.

19. Balmaev B.G., Kirov S.S., Ivanov M.A., Pak V.I. Filtration process modeling for aluminium-bearing hydrochloric acid pulp. Tsvetnye metally, 2017, no. 10, pp. 63-68. In Rus.

20. Sarpola A., Hietapelto V., Jalonen J., Jokela J., Laitinen R.S. Identification of the hydrolysis products of $\mathrm{AlCl}_{3} \cdot 6 \mathrm{H}_{2} \mathrm{O}$ by electrospray ionization mass spectrometry. Journal of Mass Spectrometry, 2004, vol. 39, pp. 423-430.

21. Ivanov V.V., Kirik S.D., Shubin A.A., Blokhina I.A., Denisov V.M., Irtugo L.A. Thermolysis of acidic aluminum chloride solution and its products. Ceramics International, 2013, vol. 39, Iss. 4, pp. 3843-3848.

22. Nalivaiko A.Yu., Lysenko A.P., Pak V.I., Ivanov M.A. Feasibility Assessment for Leucosapphire Production from Aluminum Oxide Prepared Electrochemically. Refractories and Industrial Ceramics, 2018, vol. 55, no. 1, pp. 80-84.

23. Yilmaz G. The effects of temperature on the characteristics of kaolinite and bentonite. Scientific research and essays, 2011, vol. 6, pp. 1928-1939.

24. Al-Zahrani A.A., Abdul-Majid M.H. Extraction of alumina from Local Clays by Hydrochloric Acid Process. Journal of King Abdulaziz University: Engineering Sciences, 2009, vol. 20, Iss. 2, pp. 29-41.

25. Valeev D.V., Mansurova E.R., Bychinskii V.A., Chudenko K.V. Extraction of Alumina from high-silicon bauxite by hydrochloric acid leaching using preliminary roasting method. IOP Conference Series: Materials Science and Engineering, 2013, vol. 1, Iss. 1, pp. 012049.

Received: 28 January 2019.

\section{Information about the authors}

Maxim A. Ivanov, postgraduate, National University of Science and Technology «MISIS» .

Vyacheslav I. Pak, postgraduate, National University of Science and Technology «MISIS» .

Anton Yu. Nalivayko, Cand. Sc., senior lecturer, National University of Science and Technology «MISIS».

Alexander S. Medvedev, Dr. Sc., professor, National University of Science and Technology «MISIS» .

Sergey S. Kirov, Cand. Sc., associate professor, National University of Science and Technology «MISIS» .

Galina G. Bozhko, Cand. Sc., associate professor, National University of Science and Technology «MISIS». 